\title{
INGREDIENTS OF RENDANG DALAM PENCIPTAAN KARYA FOOD PHOTOGRAPHY
}

\author{
Cindi Adelia Putri Emas
}

Institut Seni Indonesia Padangpanjang

e-mail : cindicgjl@gmail.com

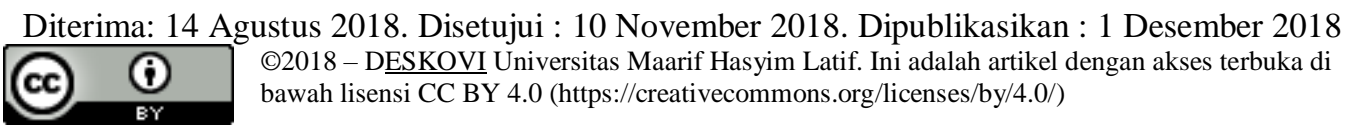

\begin{abstract}
ABSTRAK
Era globalisasi berdampak positif dan negatif yang membawa perubahan prilaku kehidupan masyarakat, seperti generasi muda lebih memilih makanan cepat saji atau junk food yang berasal dari luar negeri daripada makanan tradisional, khususnya Minangkabau. Fotografi merupakan salah satu media yang dapat digunakan sebagai langkah untuk melestarikan, menjaga, memperkenalkan, dan mempromosikan sebuah objek rempah-rempah yang merupakan bahan dasar dalam masakan Rendang dalam bentuk karya food photography. Jenis fotografi yang digunakan yaitu food photography yang merupakan spesialisasi dari commercial photography bertujuan agar memperlihatkan bahan-bahan masakan atau makanan Rendang agar terlihat menarik yang didukung dengan lighting, komposisi, penataan makanan. Metode penciptaan karya seni ini menggunakan metode konsorsium seni meliputi persiapan, elaborasi, sintesis, realisasi konsep, penyelesaian. Dengan konsep ini diharapkan rempahrempah dan bahan-bahan dalam masakan Rendang bisa dikenal publik secara luas sehingga menjaga eksistensinya serta tercipta rasa bangga dan ketertarikan terhadap makanan tradisional khusunya Rendang yang menjadi populer di kalangan generasi muda daripada makanan atau masakan luar. Ingredients of Rendang dalam Penciptaan Karya Food Photography ini sebagai langkah awal mendorong fotografer atau pembaca untuk membuat karya food photography dari setiap daerah-daerah yang ada di Indonesia agar makanan atau masakan tradisonal di Indonesia dapat dikenal oleh masyarakat luas.
\end{abstract}

Kata kunci: food photography, globalisasi, makanan tradisional, minangkabau, rendang

\section{ABSTRACT}

The era of globalization has a positive and negative impact that has brought changes in people's life behavior, as the younger generation prefers fast food or junk food originating from other country rather than traditional foods, especially Minangkabau. Photography is one of the media that can be used as a step to preserve, maintain, introduce and promote an object of seasoning which is the basic ingredient in Rendang cuisine in the food photography. The type of photography used is food photography which is a specialty of commercial photography aimed at showing Rendang food or food ingredients to make it look attractive, supported by lighting, composition, food arrangement. The method of creating this work using the art consortium method includes preparation, elaboration, synthesis, realization of concepts, completion. With this concept, it is expected that spices and ingredients in Rendang cuisine can be known to the public to maintain their existence and create a sense of pride and interest in traditional foods, especially Rendang, which is to be more popular among the younger generation rather than food from other country. Ingredients of Rendang in the Creation of Food Photography Works as a first step encourages photographers or readers to create food photography works from every region in Indonesia so that food or traditional cuisine in Indonesia can be known in all country.

Keyword: food photography, globalization, traditional food, minangkabau, rendang

\section{PENDAHULUAN}

Minangkabau merupakan salah satu etnis kultural yang ada di Indonesia. Secara geografis wilayah etnis Minangkabau tidak hanya meliputi Provinsi Sumatera Barat, tetapi juga sebagian dari Provinsi Riau, Jambi dan Bengkulu, serta etnisnya tersebar di seluruh dunia.
Minangkabau selain memiliki keunikan kultur dari segi adat istiadat, juga dikenal dengan keunikan kulinernya. Masyarakat Minangkabau memiliki berbagai macam masakan khas yang mencirikan etnis dan keberadaan budaya Minangkabau tersebut. Salah satu makanan khas Minangkabau adalah Rendang, yaitu makanan atau masakan yang berbahan utama daging bercita rasa 
pedas yang menggunakan campuran dari berbagai bumbu-bumbu dan rempah-rempah asli Minangkabau.

Akan tetapi pemilihan menu utama masakan Rendang dalam wisata kuliner bagi wisatawan masih dirasa kurang, dikarenakan era globalisasi saat ini membuat orang-orang mulai meninggalkan tradisi dan budaya. Salah satunya, generasi muda lebih memilih memakan makanan cepat saji atau junk food yang berasal dari luar negeri dari pada memakan makanan tradisional. Menyebabkan makanan dan masakan khas daerah mulai kurang digemari.

Salah satu cara memunculkan minat orang untuk memakan makanan tertentu adalah bentuk presentasi yang akan dihidangkan. Hanya sedikit orang yang ingin tahu apa saja yang terdapat dalam masakan atau makanan tersebut, seperti mengetahui bumbu-bumbu dan bahan-bahan yang ada di dalam membuat sebuah jenis produk makanan atau masakan Rendang.

Ingredients dalam bahasa Indonesia disebut dengan bahan. Bahan adalah zat atau benda yang dari mana sesuatu dapat dibuat darinya, atau barang yang dibutuhkan untuk membuat sesuatu. Dalam memasak, resep Rendang menentukan bahan yang digunakan untuk menyiapkan hidangan tertentu. Bahan-bahan tersebut diolah dan akan menjadi sebuah hidangan.

Media untuk pengaplikasian dalam pembuatan karya Ingredients of Rendang adalah fotografi. Fotografi adalah bagian ilmu yang sekarang menjadi tren tersendiri bagi beberapa golongan, baik itu golongan professional dan amatir. Fotografi dapat dikatakan sebagai bahasa gambar, yakni hasil terakhir dari bentuk tertua dari komunikasi percetakan. Berbeda dengan kata-kata verbal, bahasa gambar adalah bentuk komunikasi nonverbal yang dapat dipahami oleh seluruh dunia.

Fotografi mempunyai tiga cabang, salah satunya fotografi komersil. "Foto komersil adalah foto-foto yang berhubungan dengan dunia periklanan, seremonial, perindustrian, dan lain-lain. Dalam foto komersil, fotografer biasanya memotret objek benda hidup dan benda mati sesuai dengan permintaan klien" (Kiki Photography, 2011, p. 9).

Perkembangan dari salah satu cabang fotografi yang sedang populer adalah food photography. Beberapa kalangan tertarik food photography, baik hanya sekedar hobby atau mempunyai ketertarikan food photography. Generasi muda sekarang ketika memesan makanan dalam suatu rumah makan atau cafe, sebelum dimakan mereka mengabadikan makanan atau hidangan tersebut dan langsung diposting ke sosial media. Fotografi makanan adalah genre dari still life photography, digunakan untuk membuat ketertarikan pada still life photography makanan. "Still life Photography adalah karya foto yang menjadikan sebuah objek benda mati agar tampak menarik, tampak hidup, komunikatif, ekspresif dan mengandung pesan tertentu" (Motoyuk.com, 2013, p. 24).
Berdasarkan uraian di atas penulis tertarik menciptakan karya Ingredients of Rendang dalam Penciptaan Karya Food Photography dengan tujuan menciptakan karya Ingredients of Rendang dengan konsep lighting (tata cahaya) dalam fotografi dengan menitikberatkan kepada lighting (tata cahaya) tanpa mengenyampingkan hal-hal lain dalam fotografi serta penciptaan, proses penciptaan karya dilakukan indoor. Tujuan selanjutnya adalah memperkenalkan dan mempromosikan rempah-rempah yang merupakan bahan dasar dalam masakan Rendang dalam bentuk karya food photography. Bahan-bahan yang penulis angkat dalam meciptakan karya ini adalah semua bahan-bahan mentah dari masakan Rendang. Untuk memperkuat tema atau nuansa Minangkabau penulis mengabadikan gambar dengan peralatan pendukung khas Minangkabau, sehingga terdapatnya simbol atau tanda bahwa itu adalah bahan-bahan Rendang khas Minangkabau.

Dengan konsep ini diharapkan rempahrempah dan bahan-bahan dalam masakan Rendang bisa dikenal publik secara luas sehingga menjaga eksistensinya serta tercipta rasa bangga terhadap makanan tradisi yaitu Rendang yang menjadi populer di kalangan generasi muda dari pada makanan atau masakan luar.

\section{Landasan Penciptaan/ Teori}

Dalam proses penciptaan karya ini, penulis menggunakan beberapa teori yang menjadi acuan dasar. Sesuai dengan bentuk penciptaan karyakaryanya yakni fotografi, maka penulis menggunakan teori dasar fotografi sebagai landasan proses penciptaan, serta penggunaan cahaya yang benar dan aturan-aturan dasar lainnya yang akan menjadi displin penciptaan.

\section{Fotografi}

Awalnya fotografi tercipta dari melukis atau menggambar dengan menggunakan media cahaya. "Fotografi (dari bahasa Inggris: photography, yang berasal dari kata Yunani yaitu photos : Cahaya dan Grafo : Melukis/menulis)" (Burhanuddin, 2014, p. 2). Sebagai istilah umum, fotografi berarti proses atau metode untuk menghasilkan gambar atau foto dari suatu objek dengan merekam pantulan cahaya yang mengenai objek tersebut pada media yang peka cahaya.

\section{Fotografi Komersil}

Fotografi komersil merupakan cabang dari fotografi. "Foto komersil adalah foto-foto yang berhubungan dengan dunia periklanan, seremonial, perindustrian, dan lain-lain. Dalam foto komersil, fotografer biasanya memotret objek benda hidup dan benda mati sesuai dengan permintaan klien" (Kiki Photography, 2011, p. 9). Salah satu genre fotografi komersil adalah foto still life.

\section{Foto Still life}

Foto still life menciptakan sebuah gambar dari benda atau objek mati. Membuat gambar dari 
benda mati menjadi hal yang menarik dan tampak "hidup", komunikatif, ekspresif dan mengandung pesan yang akan disampaikan merupakan bagian yang paling penting dalam penciptaan karya foto. Foto still life bukan sekadar menyalin atau memindahkan objek ke dalam film dengan cara seadanya, tetapi menggabungkan antara konsep yang matang, teknik dan seni yang menjadi suatu kekuatan. Jenis foto ini merupakan jenis foto yang menantang dalam menguji kreatifitas, imajinasi, dan kemampuan teknis.

4. Food Photography

Food Photography salah satu genre still life photography. "Fotografi makanan adalah bagaimana membawa makanan ke tingkat yang lebih tinggi dari sekedar pemuas dahaga dan lapar" (Empatrana, 2011, p. 8). Hal yang utama dalam food Photography adalah komposisi, plating yang cantik dan penataan yang rapi. Food Photo sukses apabila berhasil menggugah selera orang yang melihatnya. Jadi selalu pastikan untuk memilih tone dan ambience yang pas, supaya makanan terlihat semakin menggoda (Motoyuk.com, 2013, p. 64).

5. Tata Cahaya ( Lighting )

Pada dasarnya, "fotografi adalah proses membuat gambar dengan merekam cahaya" (Tjin, 2011, p. 1). Ketika mengamati cahaya, hal penting yang harus diperhatikan adalah kualitas cahaya, arah cahaya, dan warna cahaya. Kualitas cahaya terbagi menjadi tiga kategori, yaitu cahaya yang keras, lembut, dan menyebar. Cahaya yang keras, lembut, dan menyebar tergantung dari ukuran sumber cahaya relative terhadap subjek foto.

Mix lighting adalah teknik kombinasi cahaya dalam fotografi. Kombinasi antara cahaya alami dan cahaya buatan. Sumber cahaya terbagi menjadi dua yaitu sumber cahaya alami dan buatan. Sumber cahaya alami yang utama adalah cahaya matahari. Hampir semua cahaya di alam ini berasal dari matahari. Sifat cahaya berbeda-beda bila cuaca berawan dan mendung. Selain beda sifatnya, warnapun sangat mempengaruhi. Cahaya buatan sering ditemui di dalam ruangan atau pada malam hari saat matahari telah terbenam. Cahaya buatan bisa bermacam-macam yaitu lampu pijar, lampu jalan, lampu neon, lampu kilat, dan sebagainya.

\section{Digital Imaging}

Digital Imaging adalah suatu proses olah digital dalam suatu software. Sebagai fotografer digital, penulis tidak bisa menghindari processing, atau editing untuk foto-foto. Penulis akan menjaga agar foto makanan tetap bersih dan menarik.

Ada beberapa software dalam hal mengedit foto di komputer, yang terbesar adalah adobe photoshop. Photoshop menawarkan sejumlah fitur dan banyak fleksibilitas, dan kemungkinan melakukan hampir apa saja yang dibayangkan dengan sebuah foto.

"Mendapatkan foto yang baik memang tidak cukup hanya berhenti pada pengertian pilihan objek yang baik saja. Pengamatan selera yang baik terhadap suatu objek dibarengi dengan keterampilan pengolahan adobe photoshop menjadi penentu kemudian" (Sugiarto, 2014, p. 116).

\section{METODE PENCIPTAAN}

\section{Persiapan}

Pada tahap ini, penulis melakukan pengamatan, pengumpulan gagasan-gagasan dan juga informasi. Mencari reverensi baik dalam bentuk buku, majalah, maupun internet.

\section{Elaborasi}

Penulis mulai menentukan ide atau gagasan yang akan menjadi fokus penciptaan. Ide serta gagasan akan menjadikan sebuah rumusan yang menjadi dasar penciptaan karya.

3. Sintesis

Dalam proses ini, penulis mulai membayangkan bentuk yang akan diciptakan berdasarkan atas ide pertama dan gagasan yang telah didapat dan penyatuan informasi-informasi. Pengimajinasian sebuah bentuk yang akan dibuat dalam penciptaan ini.

4. Realisasi Konsep

Realisasi konsep merupakan tindak lanjut dari tahap sentesis. Realisasi konsep akan berbentuk karya fotografi. Yang berarti sebuah "seni, ilmu pengetahuan dan praktik menciptakan gambar yang tahan lama dengan merekam cahaya atau radiasi elektromagnetik, baik secara kimia dengan menggunakan film fotografi atau secara eletronik melalui sebuah sensor gambar" (Sudarman, 2014, p. 2). Penulis mulai bekerja di dalam studio. Mencoba merealisasikan apa yang telah dipersiapkan dan juga dibayangkan sebelumnya.

5. Penyelesaian

Tahap penyelesaian ini adalah tahap akhir dari proses berkarya yaitu, pelaksanaan pameran. Pada proses pameran penulis memamerkan karya fotografi di galeri Taman Budaya Padang yang berjumlah dua puluh buah karya fotografi. Yang akan diuji, dinilai dan dinyatakan layak oleh kurator.

\section{PEMBAHASAN}

Ulasan karya ditampilkan foto beserta uraian penjelasannya. Semua karya foto yang ditampilkan merupakan hasil dari pemotretan dengan metode lighting yang berada di dalam ruangan atau indoor. Karya foto tersebut merupakan foto food photography yang terfokus pada Ingredients of Rendang. Semua foto menggunakan bahan-bahan asli Minangkabau. Properti yang digunakan seperti pangua dan batu lado berfungsi sebagai objek pendukung yang dapat membuat ciri khas Minangkabau terdapat didalam karya tersebut.

Karya fotografi Ingredients of Rendang dalam Penciptaan Karya Food Photography mempunyai tiga bagian. Bagian pertama dalam karya fotografi ini adalah Ingredients of Rendang dengan memotret bahan-bahan tunggal asli Minangkabau 
dalam pembuatan Rendang yaitu laos, jahe, bawang merah, bawang putih, cabai, daun kunyit, daun salam, daun jeruk, daging, garam, kelapa, dan serai. Bagian kedua mengelompokkan bahan-bahan Rendang menjadi kelompok umbi-umbian dan daun-daunan. Bagian ketiga adalah foto keseluruhan bahan-bahan yang terdapat masakan atau makanan Rendang serta memasukkan Rendang yang telah jadi sebagai pertanda bahan-bahan tersebut adalah bahan-bahan masakan atau makanan Rendang. Jadi, penulis akan menyusun karya yang telah siap untuk didispaly dengan tiga bagian, ukuran bagian pertama $40 \times 60 \mathrm{~cm}$, bagian kedua $50 \times 75 \mathrm{~cm}$, bagian ketiga $60 \times 90 \mathrm{~cm}$, membuat karya bagian ketiga dengan ukuran besar karena karya akhir yang menyatukan seluruh bahanbahan Redang dan masakanan atau makanan Rendang yang telah jadi dalam satu frame. Menghadirkan instalasi berupa tempat masak Rendang tradisional (tungku) dengan kuali, kayu bakar, batu lado, pangua dan semua bahan-bahan Rendang. Semua karya foto yang dihasilkan merupakan pemotretan di akhir tahun 2016 dan awal tahun 2017, begitu juga dengan proses dalam pencetakkannya hingga menjadi karya foto yang siap didisplay dan dipamerkan.

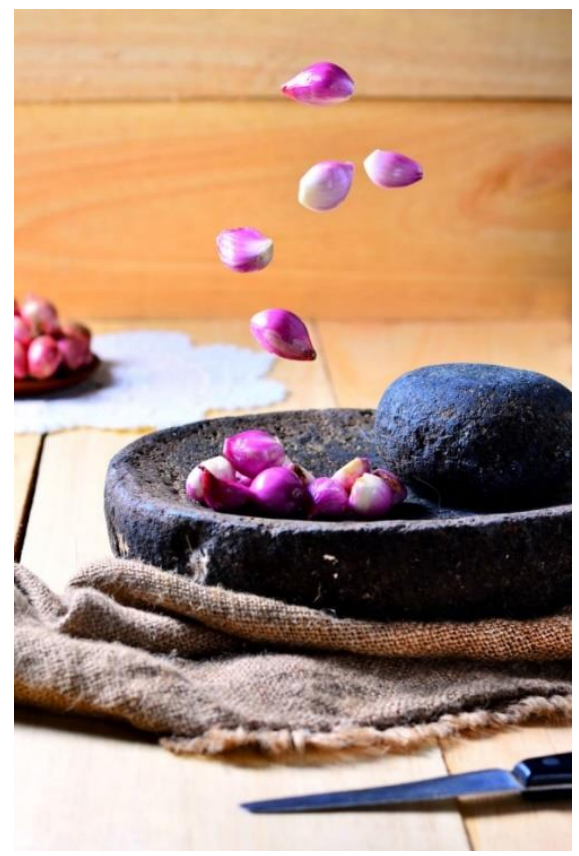

Gambar 1.Raso dibaok naiak, pareso dibawok turun Ukuran foto $40 \mathrm{~cm} \times 60 \mathrm{~cm}$ Paper glossy laminanting doff 2017

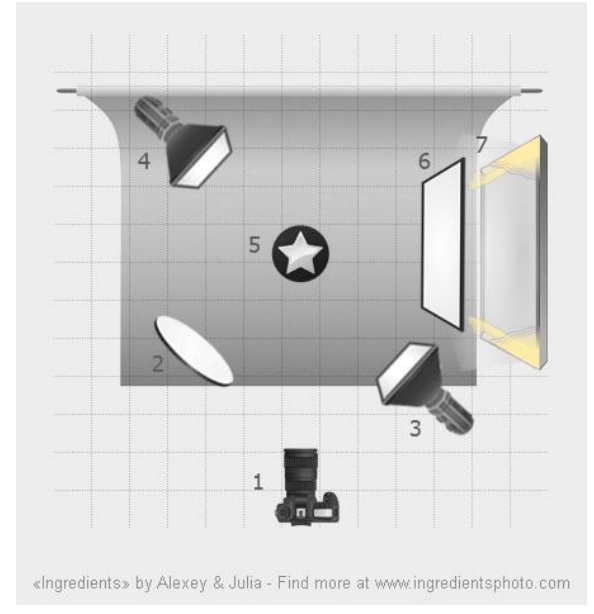

Gambar 2 : Pengaturan Alat

Keterangan gambar 2 :

1. Kamera

2. Reflector

3. Softbox (main light)Softbox (fill light)

4. Objek

5. Diffuser

6. Window

Foto ini merupakan karya ketiga yang bertemakan Ingredients of Rendang yaitu bawang merah. Karya ketiga ini berjudul Raso Dibaok Naik, Pareso Dibaok Turun bermakna kecerdasan dan perasaan. Kita sebagai makhluk hidup diberi oleh Allah SWT kecerdasan dan perasaan maka dari itu harus menjaga kecerdasan dan perasaan itu, menempatkan di tempat yang benar. Ketika bawang merah ini dilempar maka harus terletak ditempat yang semestinya (batu lado) begitu juga dengan manusia. Dalam karya ini menggunakan peralatan pendukung batu lado yaitu ulekan khas Minangkabau untuk memberikan ciri khas Minangkabau dan membuat selera untuk memakan makanan atau masakan Rendang karena bawang merah yang digiling dengan batu lado akan membuat cita rasa yang berbeda dari pada menggiling bawang merah dengan blender.

Pengambilan karya ini menggunakan lensa Nikon kit $118 \mathrm{~mm}-55 \mathrm{~mm}$ dengan settingan focal length 50mm, kecepatan 1/100, diafragma $\mathrm{f} / 4$ dan ISO 100. Pemotretan karya ini dilakukan di indoor dengan cahaya matahari terletak disamping kanan dan diffuser di depannya. Softbox di samping depan kanan dan samping kiri belakang serta reflektor di samping kiri depan untuk memantulkan cahaya, mengisi cahaya pada bagian sebelah kiri yang kosong. Menggunakan background papan dan menggunakan tenik freezing. 


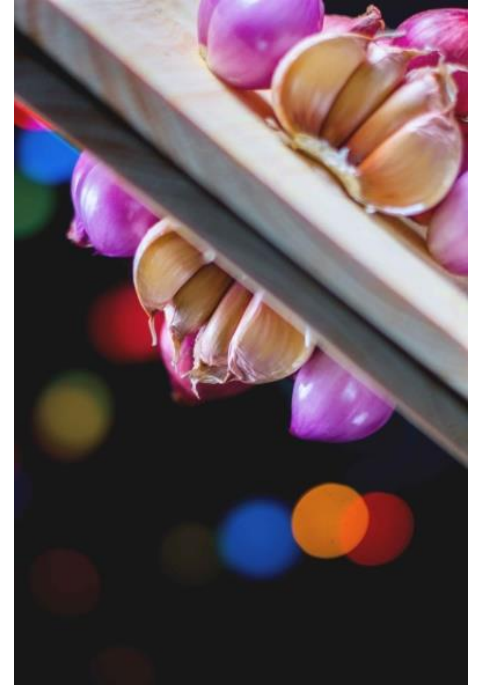

Gambar 3.Refleksi rasa Ukuran foto $50 \mathrm{~cm} \times 75 \mathrm{~cm}$ Paper glossy laminanting doff 2017

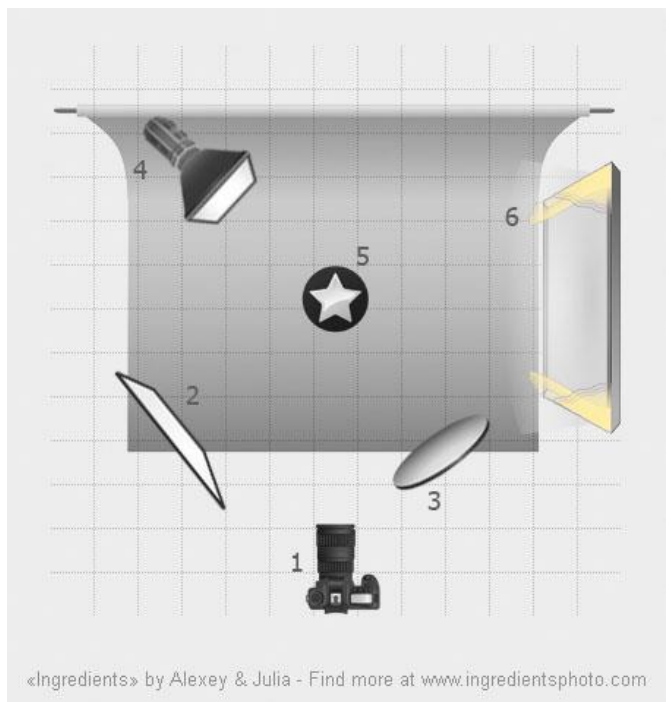

Gambar 4.Pengaturan alat

Keterangan gambar 4 :
1. Kamera
2. Styrofoam
3. Reflector
4. Softbox
5. Objek
6. Window

Foto ini merupakan karya ketigabelas yang bertemakan Ingredients of Rendang bagian kedua dengan pengelompokkan berdasarkan umbi-umbian yaitu bawang merah dan bawang putih. Karya ini berjudul Refleksi Rasa. Oleh karena itu objek pengambilan foto dalam karya ini adalah dari refleksi bawang merah dan bawang putih yang memiliki rasa yang khas ketika di masak pada masakan atau makanan Rendang.
Pengambilan karya ini menggunakan lensa Nikon fix $50 \mathrm{~mm}$ dengan setting focal length $50 \mathrm{~mm}$, kecepatan 1/125, diafragma f/1.8 dan ISO 100. Pemotretan karya ini dilakukan di dalam ruangan dengan cahaya matahari terletak di sebelah kanan, softbox di sebelah kiri belakang agar mendapatkan rim light. Reflektor dan styrofoam terdapat di kanan depan dan kiri depan untuk memberikan fill light. Dalam pemotretan ini menggunakan alat pendukung lampu kelap klip untuk backgroundnya dengan menggunakan diafragma besar sehingga cahaya pada lampu kelap kelip terlihat membulat serta menggunakan kaca sebagai media refleksi pada objek.

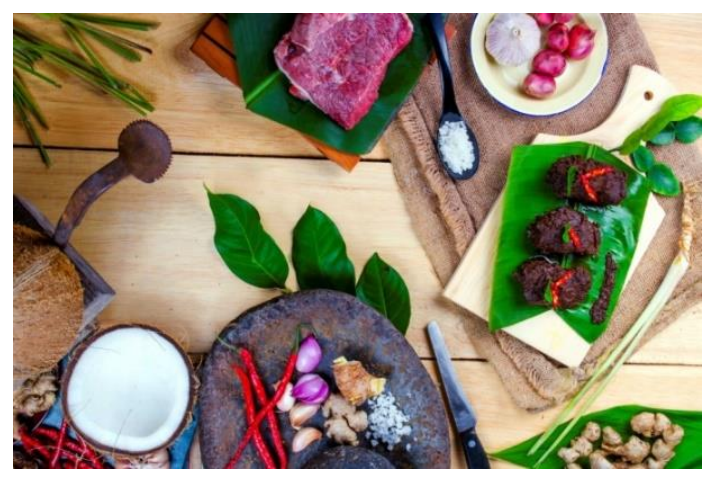

Gambar 5.Turun ka tangah

Ukuran foto $60 \mathrm{~cm} \times 90 \mathrm{~cm}$ Paper glossy laminanting doff 2017

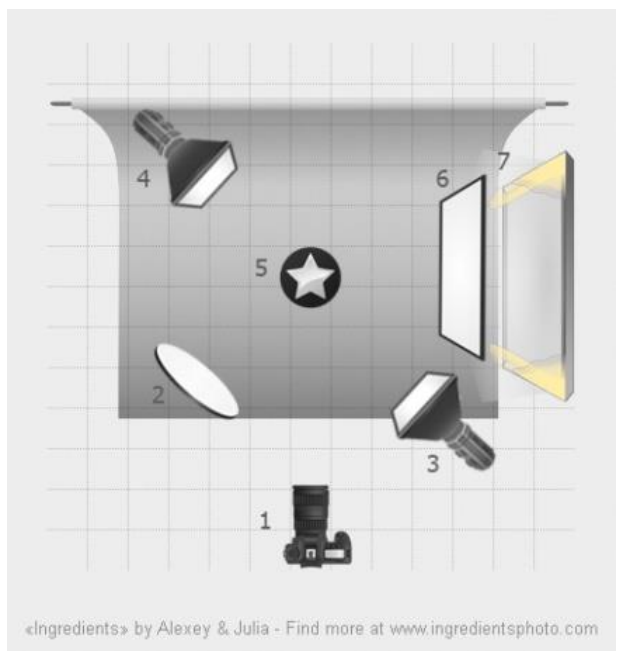

Gambar 6.Pengaturan Alat

Keterangan gambar 6 :
1. Kamera
2. Reflector
3. Softbox
4. Softbox
5. Objek
6. Diffuser
7. Window 
Foto ini merupakan sembilanbelas yang bertemakan Ingredients of Rendang bagian ketiga dengan hadirnya semua bahan-bahan makanan Rendang serta makanan atau masakan Rendang yang telah jadi. Penggambilan karya ini menggunakan lensa Nikon kit $118 \mathrm{~mm}-55 \mathrm{~mm}$ dengan settingan focal length 28mm, kecepatan 1/100, diafragma f/10 dan ISO 100. Pemotretan karya ini dilakukan di indoor dengan cahaya matahari terletak disamping kanan dan diffuser di depannya. Softbox di samping depan kanan dan samping kiri belakang serta reflektor di samping kiri depan.

Judul karya ini adalah Turun Ka Tangah karena dalam upacara atau adat Minangkabau Rendang diletakkan di dekat para datuk (datuak) dan tetua adat. Orang Minangkabau menyebutnya sebagai kapalo jamba (kepala hidangan). Setelah para tetua adat berbicara diselingi aneka pantun, acara makan dimulai. Setelah yang tua mengambil makanan maka yang muda baru boleh mengambil makanan.

Pemotretan ini menggunakan alat pendukung khas Minangkabau yaitu pangua yang berfungsi sebagai pemarut kelapa dan batu lado yaitu ulekan khas Minangkabau, karena bawang merah yang digiling dengan batu lado akan membuat cita rasa yang berbeda dari pada menggiling bawang merah dengan blender, begitu juga dengan kelapa. Ketika memarut kelapa menggunakan pangua akan berbeda cita rasanya dengan mesin. Menggunakan pangua membuat santan lebih enak. Biasanya orang Minangkabau hanya menggambil perasan kelapa (santan) kesatu dan kedua, karena pada perasan pertama dan kedua kualitas santan bagus dan kental. Sehingga membuat selera makan seseorang akan meningkat.

\section{KESIMPULAN}

Pembuatan karya Ingredients of Rendang dalam Penciptaan Karya Food Photography ini membutuhkan beberapa tahapan dalam proses pembuatannya. Proses pertama adalah meliputi persiapan, elaborasi, sintesis, realisasi konsep, dan penyelesaian.

Semoga bermanfaat dan menambah wawasan bagi generasi muda Minangkabau khususnya, dan masyarakat pada umumnya. Dapat mengetahui bahanbahan asli Minangkabau dari masakan atau makanan Rendang yang membuat ketertarikan generasi muda akan masakan atau makanan tradisonal khususnya Rendang dari pada makanan cepat saji atau junk food, sehingga menjaga eksistensi Rendang sebagai makanan produk lokal yang mampu bersaing dan bertahan dalam produk nasional. Kiranya ini dapat berguna sebagai arsip dan memajukan pariwisata khususnya di bidang kuliner.

\section{DAFTAR PUSTAKA}

Burhanuddin. (2014). Fotografi. Yogyakarta: Graha Ilmu.

Empatrana. (2011). Food Photography Made Easy. Jakarta: Kompas Gramedia.

Hoddinott, R. (2013). Lense for Digital SLRs. Jakarta: Elex Media Komputindo.

Kiki Photography. (2011). Tips Praktis Bisnis Fotografi. Jakarta: Grasindo.

Manna, L. (2005). Digital Food Photography. Boston: Course Technology.

Motoyuk.com. (2013). My Photography Compendium Series. Jakarta: Kompas Gramedia.

Sudarman, I. K. (2014). Fotografi. Yogyakarta: Graha Ilmu.

Sugiarto, A. (2014). Seni Digital. Jakarta: Elex Media Komputindo.

Tjin, E. (2011). Lighting itu Mudah! Jakarta: Bukune 
Cindi Adelia Putri Emas / DESKOVI : Art and Design Journal, Vol. 1, No.1, Desember 2018, 45-52

(Halaman ini sengaja dikosongkan) 